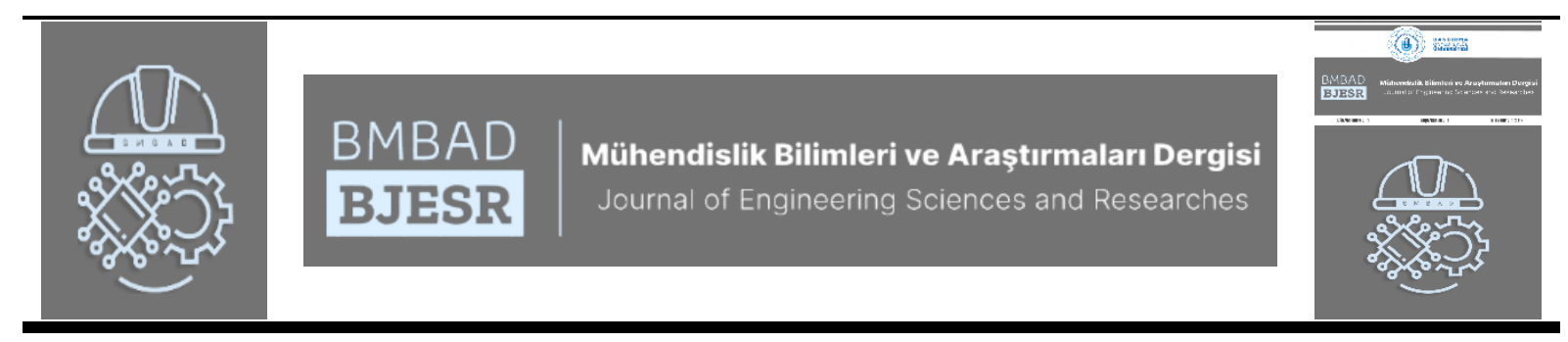

\title{
Su Borusu Hatlarında Sızıntı tespitinde Yer Radari Yöntemi Uygulaması (GPR)
}

\section{Application of Ground Penetrating Radar (GPR) Method in Leak Detection in Water Pipeline}

\author{
${ }^{1}$ Hakan KÜTÜKCÜOĞLUGIL (D) ${ }^{2}$ Sinan KOŞAROĞLU \\ ${ }^{I}$ Sivas DSİ, 19.Bölge Müdürlüğ̈̈, Sivas, Türkiye \\ ${ }^{2}$ Sivas Cumhuriyet Ünivsersitesi,Mühendislik Fakültesi,Sivas, Türkiye \\ ${ }^{3}$ Sivas Cumhuriyet Ünivsersitesi,Mühendislik Fakültesi,Sivas, Türkiye \\ 1'hakankutukcuoglugil@gmail.com, 22skosaroglu@ cumhuriyet.edu.tr, \\ 3fbilim@cumhuriyet.edu.tr
}

AraştırmaMakalesi/Research Article

A R T I C LE IN F O

Article history

Recieved : 13 September 2021

Accepted : 14 October 2021

Key Words:

CTP pipeline, GPR, Nevruz Dam

\section{A B S T R A C T}

In this study, the detection of leaking water in CTP pipelines by ground penetrating radar method (GPR) was investigated. During the construction of the Nevruz Dam irrigation field, which is under construction in the Yildizeli district of Sivas province, while the pipeline was being laid, a plastic pipe was left on the pipeline with one end on the surface, and the surface was smoothed by covering it. Here, measurements were taken with 2 different GPR devices at $160 \mathrm{MHz}, 625 \mathrm{MHz}$ and $250 \mathrm{MHz}$ frequencies. The experiment was carried out in 3 stages. In the first stage, measurements were taken at $160 \mathrm{MHz}$ and $625 \mathrm{MHz}$ frequencies when the medium was dry. In the second stage, 8 tons of water was left on the pipeline with the help of the pipe on the surface, and the presence of water was tried to be determined based on the existence of water leakage in the pipeline and the results were presented.
M A K A L E B İ L G İ S İ

\section{Makale Tarihleri}

Gönderim: 13 Eylül 2021

Kabul : 14 Ekim 2021

\section{Anahtar Kelimeler:}

CTP boru, GPR, Nevruz Baraj1

\section{Ö Z E T}

Bu çalışmada CTP boru hatlarındaki sızıntı kaçak suların yer radarı yöntemi ile tespiti incelenmiştir. Sivas ili Yıldızeli ilçesinde yapımı devam eden Nevruz Barajı sulama sahası inşaatında boru hattı döşenirken bir ucu yüzeyde olmak üzere boru hattına plastik boru bırakılmış, üzeri kapatılarak yüzey düzgün hale getirilmiştir. Burada $160 \mathrm{MHz}, 625 \mathrm{MHz}$ ve $250 \mathrm{MHz}$ frekansta 2 farklı Yer Radarı (GPR) cihazı ile ölçü alınmıştır. Deney 3 aşamalı olarak gerçekleştirilmiştir. Birinci aşamada ortam kuru iken 160 $\mathrm{MHz}$ ve $625 \mathrm{MHz}$ frekanslarda ölçü alınmıştır. İkinci aşamada yüzeydeki boru yardımıyla boru hattı üzerine 8 ton su bırakılmış, boru hattında su kaçağı var olduğundan yola çıkarak suyun varlığı tespit edilmeye çalışılmış ve sonuçları değerlendirilmiştir. 


\section{GİRIŞ}

Yer radarı yöntemi (GPR) tahribatsız jeofizik yöntemi olup, sı̆̆ yeraltı yapılarının görüntüsünü verir. Yöntemin temeli yüksek frekanslı elektromanyetik (EM) dalganın yer içindeki yayılımı, yansıması ve saçılmasına bağlıdır. Yüksek frekanslı (genellikle 20-2000MHz) EM dalgası yer içerisine verici anten ile gönderilir ve geri dönen EM dalga sinyal alıcı anten ile kaydedilir. Kaydedilen sayısal sinyaller veri-işlem aşamalarından sonra çift-yol zamanlı düşey kesitlere (radargram) dönüştürülür ve yorumlanır. EM yansımaları iki farklı dielektrik özelliğine sahip ortam arasında gerçekleşir. Yani, yeraltında farklı fiziksel ve kimyasal özelliklere sahip sınırda dalganın bir kısmı yansır ve alıcı tarafından kaydedilir. Ortamın dielektrik değeri toprağın tane büyüklüğüne, kil içeriğine, gözenekliliğine, su içeriğine ve parçacıkların elektrik özelliklerine göre değişkenlik gösterir. GPR sonuçları yeraltı jeolojisine ve seçilen anten frekansına bağlıdır.

GPR çalışmalarını etkileyen en önemli faktörlerden birisi anten frekansıdır. Çalışmalarda kullanılan anten frekansları genellikle $20 \mathrm{MHz}-2 \mathrm{GHz}$ arasındadır (Şekil 1) [1]. Uygulama derinliğine göre anten tipi yani frekans da değişmektedir. Yüksek frekanslı EM dalgalar daha sığ derinliklerden bilgi alınmasını sağlarken gürültüyü de artırabilir. Düşük frekanslı EM dalgaların penetrasyon derinliği yüksek olmasına karşın detay ve çözünürlülük daha azdır (Tablo 1). Anten frekansı seçimi yapılırken; çalışma ortamının jeolojik özellikleri (kırıklı, çatlaklı olması, gözenekliliği, geçirgenliği vb.), suya doygunluğu ve kil içeriği, araştırılacak materyalin boyutu ve derinliği dikkate alınmalıdır. Çalışma sahasında toplanan veriler sayısaldır ve veriler genellikle gürültülüdür. GPR verileri bir dizi veri işlemden geçerek önce radargramlar haline daha sonra da üç boyutlu hale getirilir. Araziden alınan verilerde bozuk (çok yüksek veya düşük) veriler süzgeçleme aşamasında atılamayacak durumda ise veri işlem aşamasına sokulmaz ve yorumlanmaz. Veri işlem aşamaları sırasıyla, statik düzeltme, dewow, enerji geri kazanımı, hız kazanımı, band geçişli süzgeçleme ve saçılmış izleri toplayarak gerçek yerlerine taşıma işlemi olan migrasyon işleminden oluşmaktadır.

GPR yöntemi, yüksek çözünürlüklü olması ve yeraltındaki cisimlerin konum ve büyüklerini tespit etmesi nedeniyle; fay, kırık ve çatlakların haritalanmasında [2], yer altı karstik boşlukların [2], yer altı su seviyesinin [3], arkeolojik kalıntıların [4] tespiti gibi birçok alanda kullanılmaktadır. Son yıllarda gömülü borularda sızıntı tespitine yönelik GPR uygulamaları hız kazanmıştır [5, 6, 7]. Ayala-Cabreravd. (2014), laboratuvar koşullarında kum-kil doldurulmuş tahta sandık içerisine PVC (polivinil klorür) boru yerleştirmiş ve sandık üzerine polikarbon bir plaka koyarak GPR ölçümü bu plaka üzerinde gerçekleştirmiştir. Amran (2017), Malezya Nükleer Ajansı laboratuarında kum havuzuna gömülmüş demir ve PVC borular üzerinde GPR ölçümlerini borularda su yokken ve su enjekte edildiğinde olmak üzere iki aşamada gerçekleştirmiştir. Araştırmacı içinde su bulunan çelik borunun boş çelik boruya göre radargramlarda daha büyük hiperboller gösterdiğini gözlemlemiştir. Kavi (2018), ise gömülü metalik olmayan boruların (CTP ve PVC) tespitinde GPR yöntemini kullanmıştır. Bunun için kapkarbon kumaş ve alüminyum folyo ile kaplanan ve kaplanmayan boruları gömmüştür. Ölçümlerin değerlendirmesi sonucunda karbon kumaş veya alüminyum folyo ile kaplanan boruların radargramlarda daha iyi belirti verdiği saptanmıştır.

$\mathrm{Bu}$ çalışmada ise, PVC su borularının su ihtiva etmesi ya da etmemesi durumlarında GPR yöntemine verdiği yanıtlar ve yer altındaki gömülü borularda su kaçağı olması durumunda GPR yöntemi ile saptanıp saptanamayacağı irdelenmiştir.

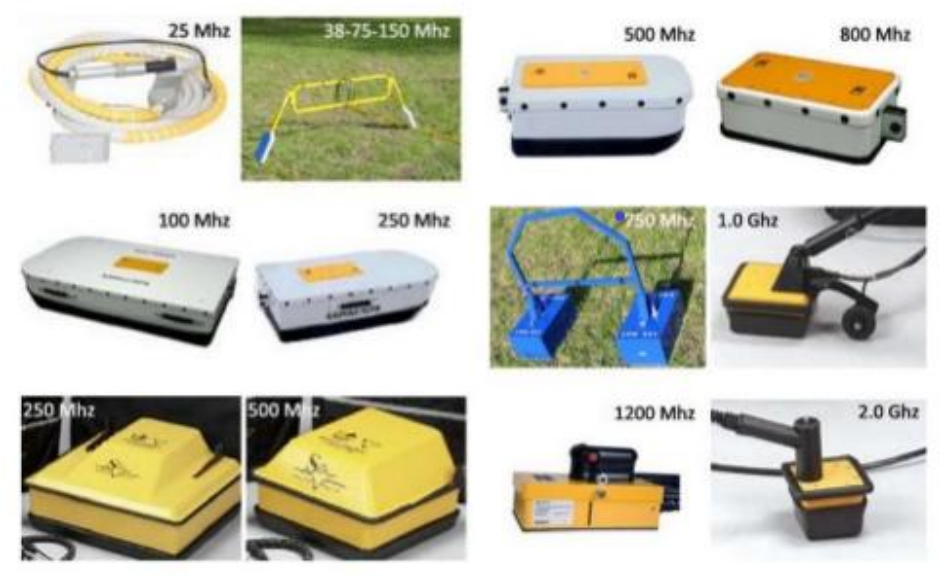

Şekil 1. GPR anten çeşitleri [1]

Tablo1. Frekansın derinlik ve çözünürlük ile olan ilşkisi

\begin{tabular}{lll}
\hline Frekans (20 MHz-2 GHz) & Penetrasyon & Düşey çözünürlük \\
\hline Düşük (<1 GHz) & Yüksek & Düşük \\
Yüksek $(>1 \mathrm{GHz})$ & Düşük & Yüksek \\
\hline
\end{tabular}




\section{2. ÇALIŞMA ALANI}

Çalışma alanı olarak Sivas İli Yıldızeli İlçesinde inşaatı devam Nevruz Barajı sulama sahası seçilmiştir (Şekil 2). GPR ölçümlerine başlamadan önce inşaat devam ederken alana boru hattı döşenip yastıklama malzeme konulduktan sonra, deneyde kullanılacak düzenek yapılmıştır ve çalışma sahasına 1,5 m çapında CTP boru döşenmiştir (Şekil 3). Alan daha sonra şeritmetreler ile çevrelenerek çalışma sahası oluşturulmuş ve $1 \mathrm{~m}$ aralıklarla işaretlenerek karelaj yapılmıştır (Şekil 4).

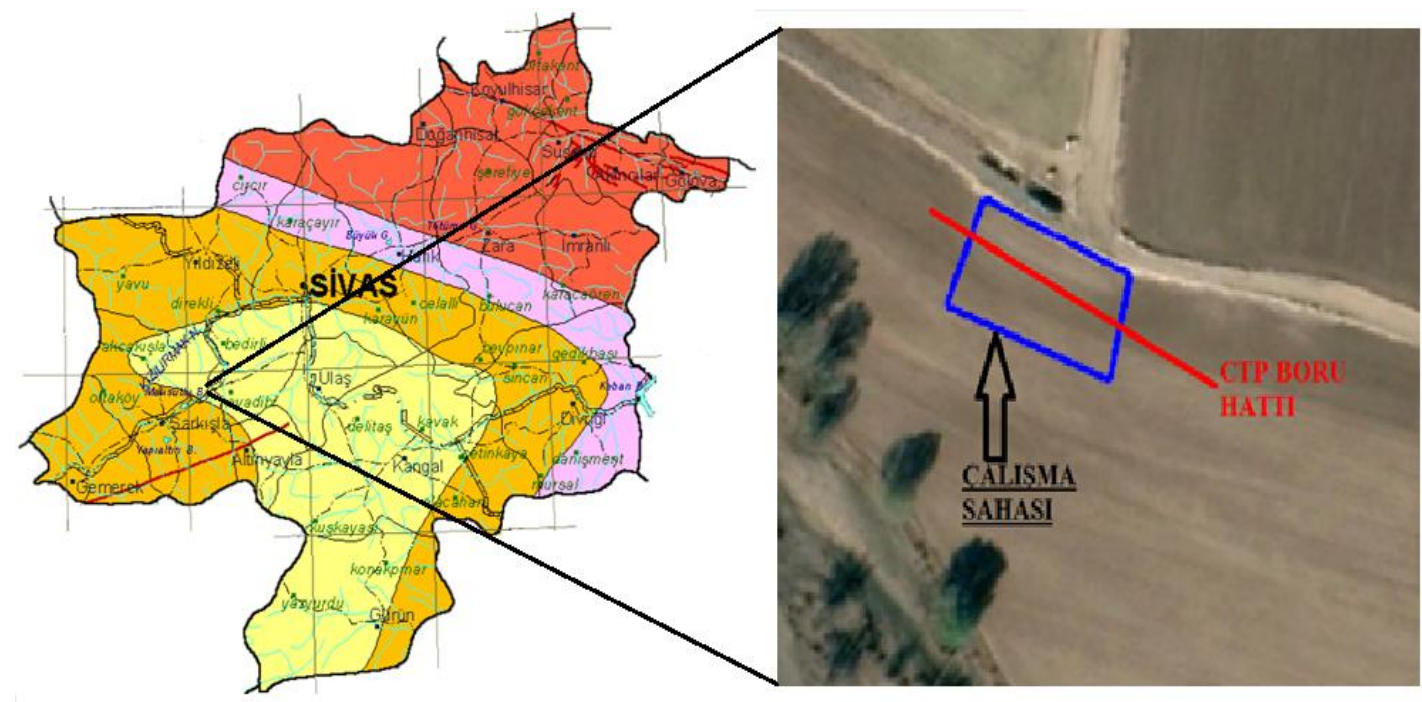

Şekil 2. Nevruz (Sivas-Yıldızeli) alanı ve çalışma sahasının yer bulduru haritası.

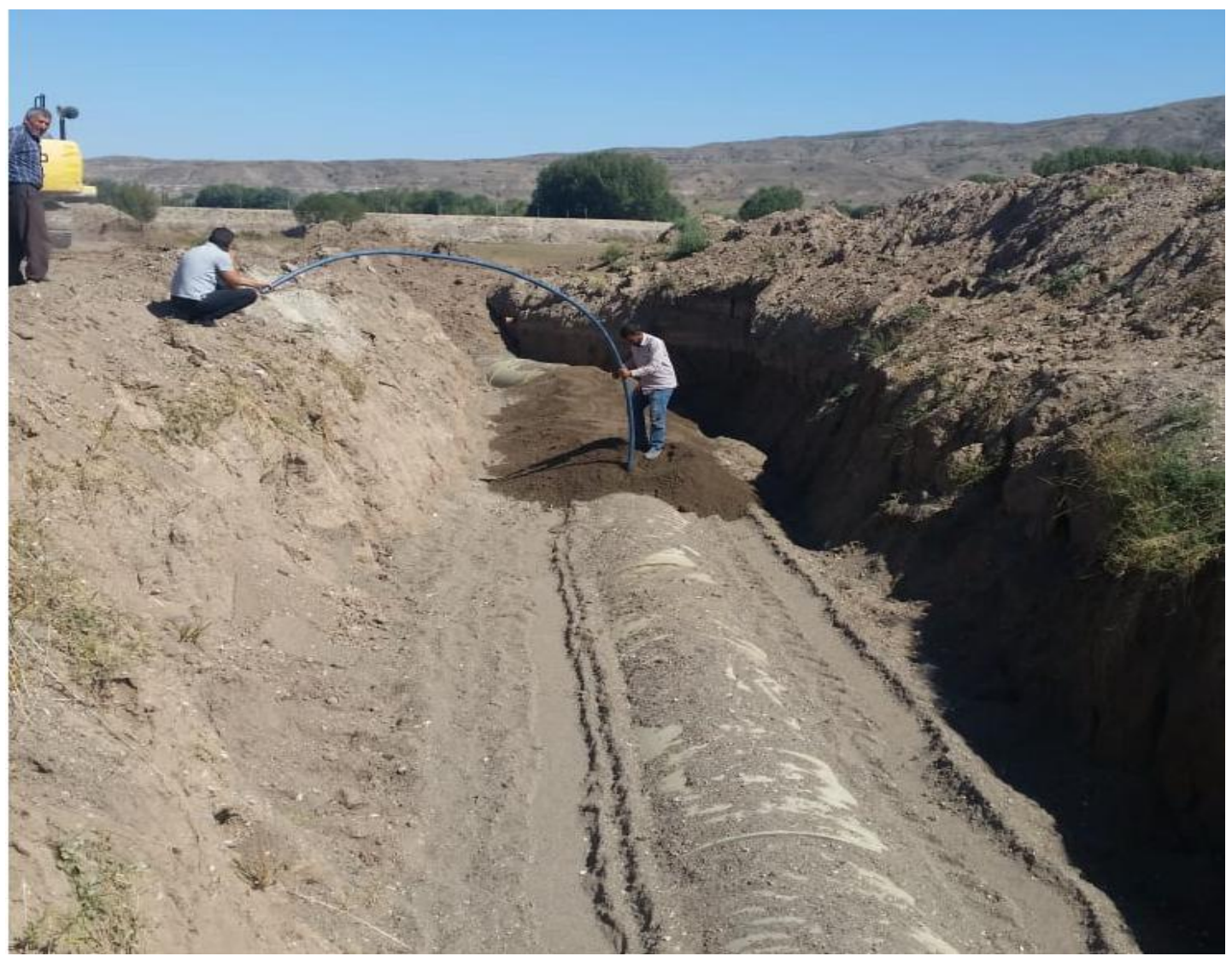

Şekil 3. Arazide borunun döşenmesi. 
Döşenen boru cam elyaf takviyeli plastic (CTP) özelliğinde olup, CTP malzeme ise polyester bazlı reçine ile cam elyafın birleştirilmesinden oluşan bir malzemedir.

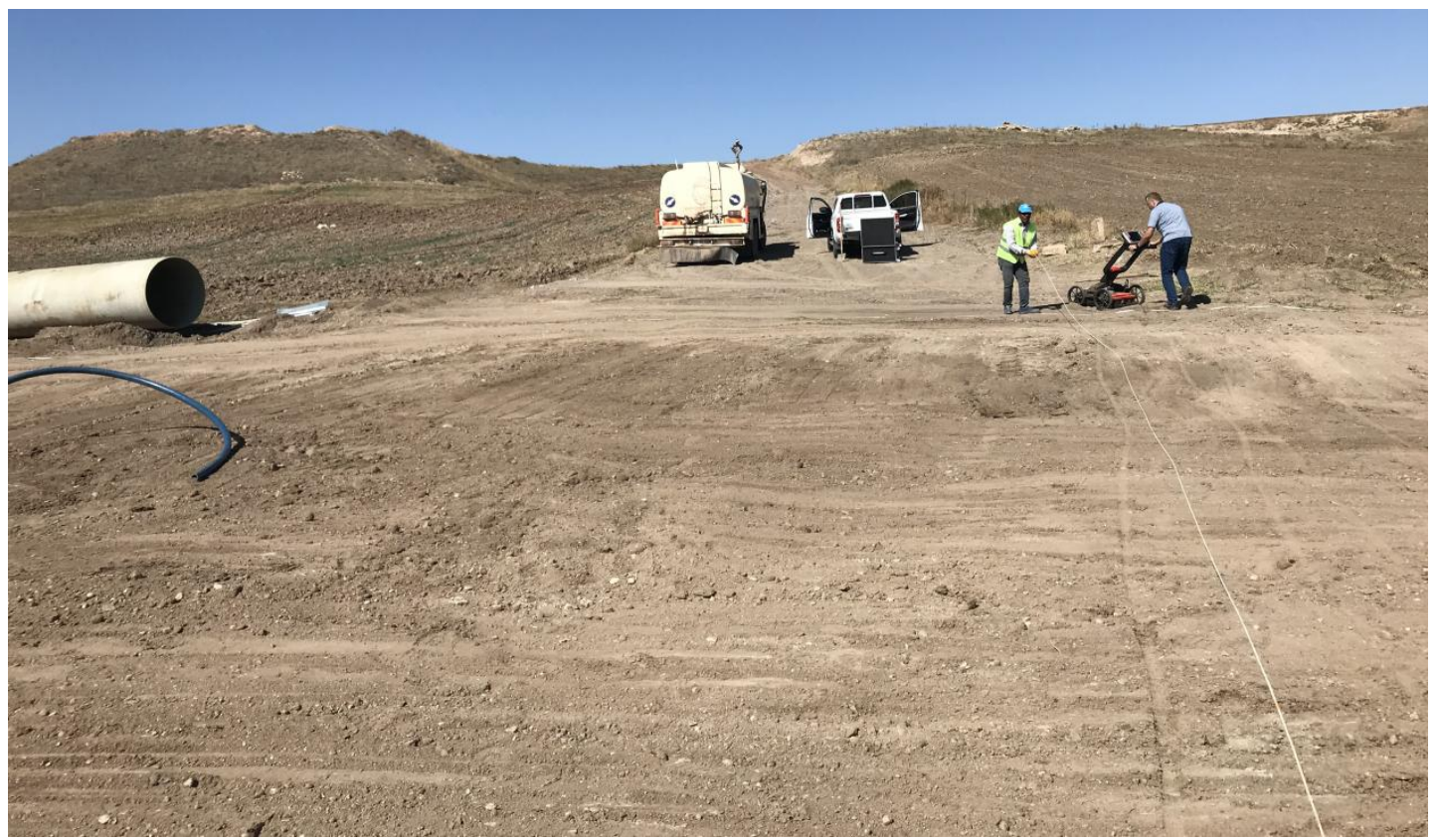

Şekil 4. Çalışma alanının ölçüm için hazırlanması.

\section{GPR ÖLÇÜMLERININ ALINMASI}

$16 \mathrm{~m}-27 \mathrm{~m}$ boyutlarında ki çalışma alanı $1 \mathrm{~m}$ aralıklarla karelajlandırılarak toplam 129 profil GPR ölçümü alınmış̧ır (Şekil 5).

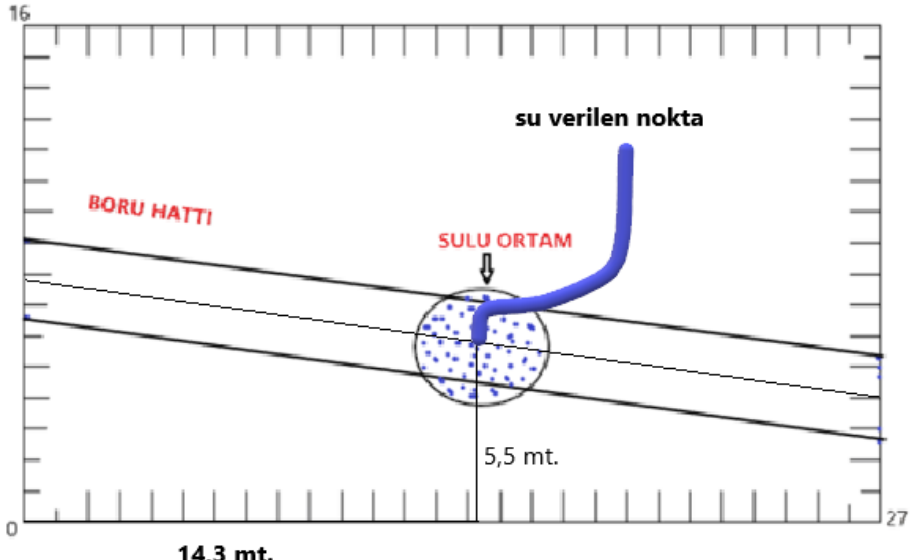

Şekil 5. Ölçüm noktaları.

Ölçümlerin alımında Mala firmasının üretmiş olduğu merkezi anten frekansı $250 \mathrm{MHz}$ olan korumalı anten sistemi ve aynı firmanın üretmiş olduğu $80-950 \mathrm{MHz}$ bant aralığına sahip korumalı anten kullanılmışıtır. Çalışma alanında önce kuru ortamda x ve y yönünde 625-160-250 MHz anten seti ile $1 \mathrm{~m}$ aralıklı olacak şekilde ölçüm verileri toplanmıştır (Şekil 6). İkinci aşamada sulu ortam ölçümü gerçekleştirilmiştir. Bunun için daha önce CTP hattı döșenirken konulan borudan su tankeri yardımıyla 8 ton su, boru hattının etrafına verilmiştir (Şekil 7) ve kuru ortam için alınan aynı hatta, aynı cihaz ile ölçümler alınmıştır. Alınan ölçümlere temel veri işlem adımları uygulanmıştır. 
Müh.Bil.ve Arass.Dergisi,2021;3(2) 235-244

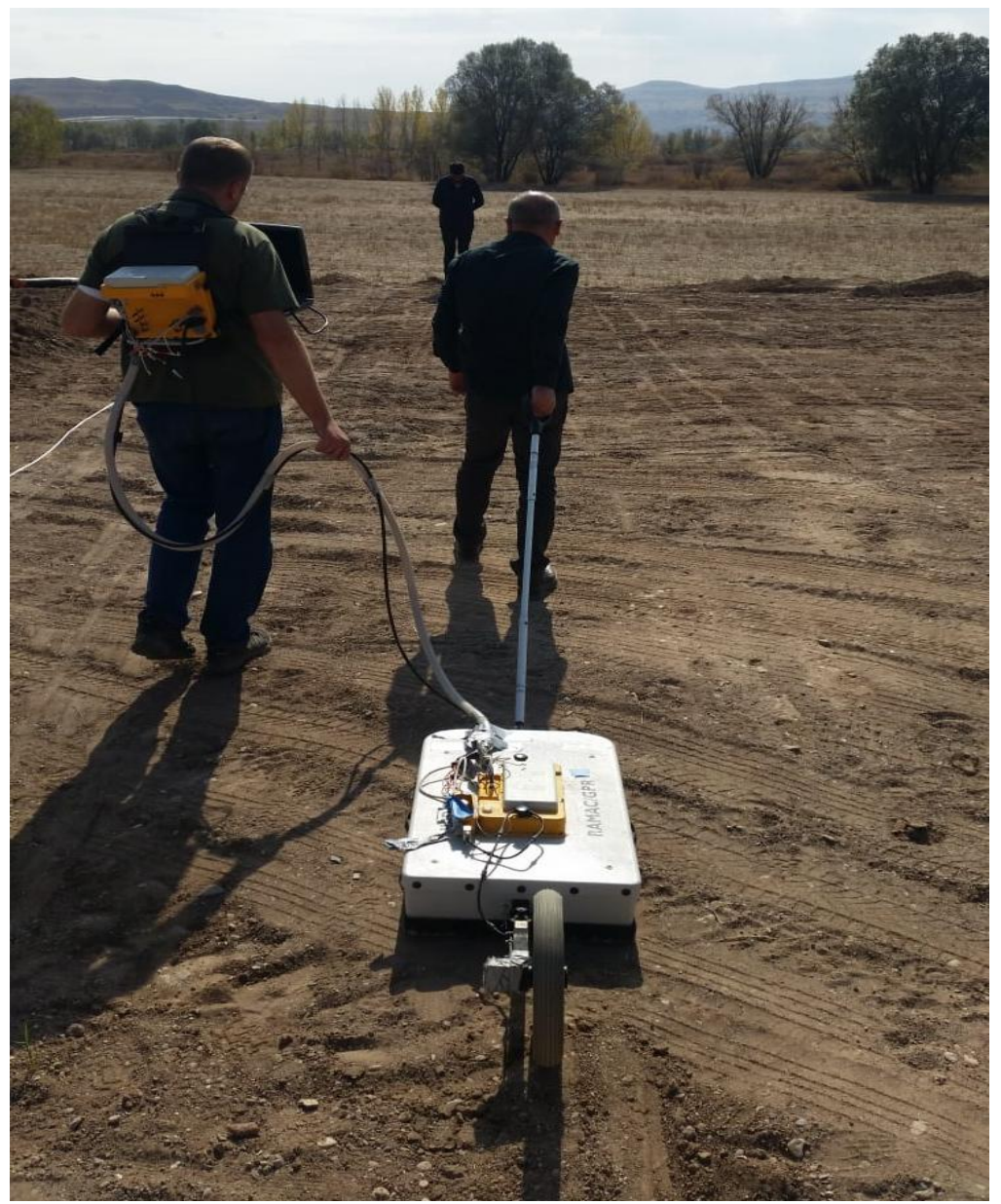

Şekil 6. GPR ölçümü.

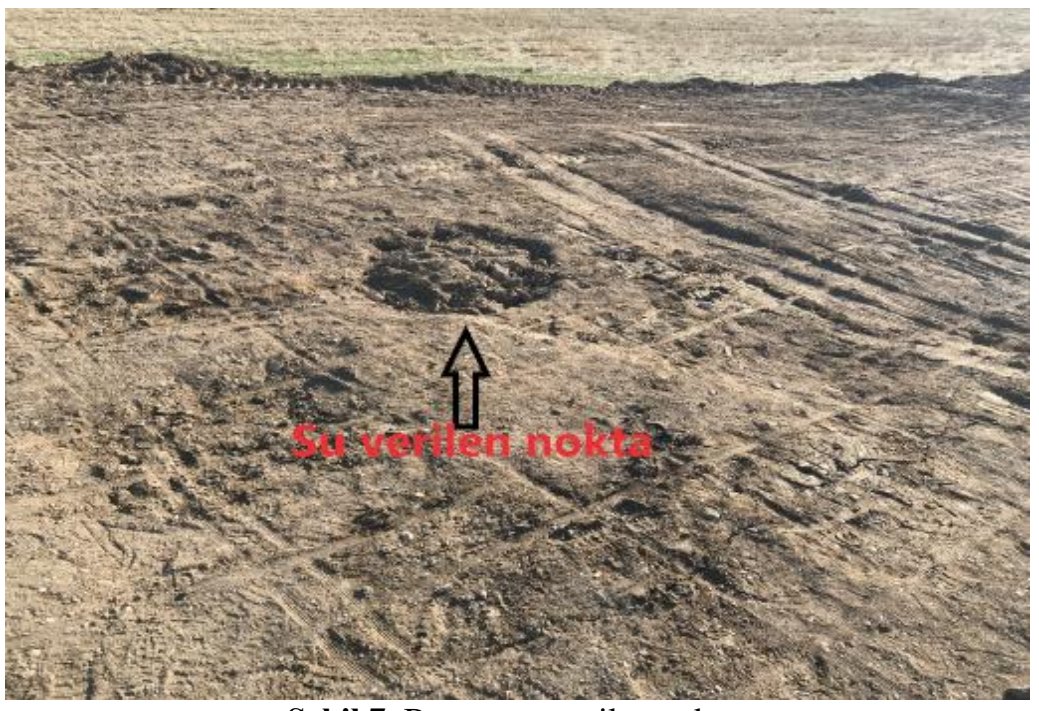

Şekil 7. Boruya su verilen nokta. 


\section{BULGULAR}

Veri işlem aşamasından sonra ölçümler birleştirilerek üç boyutlu yeraltı görüntüleri elde edilmiştir. Üç boyutlu ekran aralıkları $10 \mathrm{nsn}$ 'dir. Veriler her $50 \mathrm{~cm}$ 'de bir kesilerek 0.5 ve $1.0 \mathrm{~m}$ derinlik seviyelerinde ki değişiklikler incelenmiştir. Şekil 8, 9, 10, 11'de verilen kesitlerde; a) $625 \mathrm{MHz}$, b) $160 \mathrm{MHz}$, c) $250 \mathrm{MHz}$ anten ile kuru ortamda alınmış ölçüleri, d) $625 \mathrm{MHz}$, e) $160 \mathrm{MHz}$ anten ile sulu ortamda alınmış ölçüleri göstermektedir.
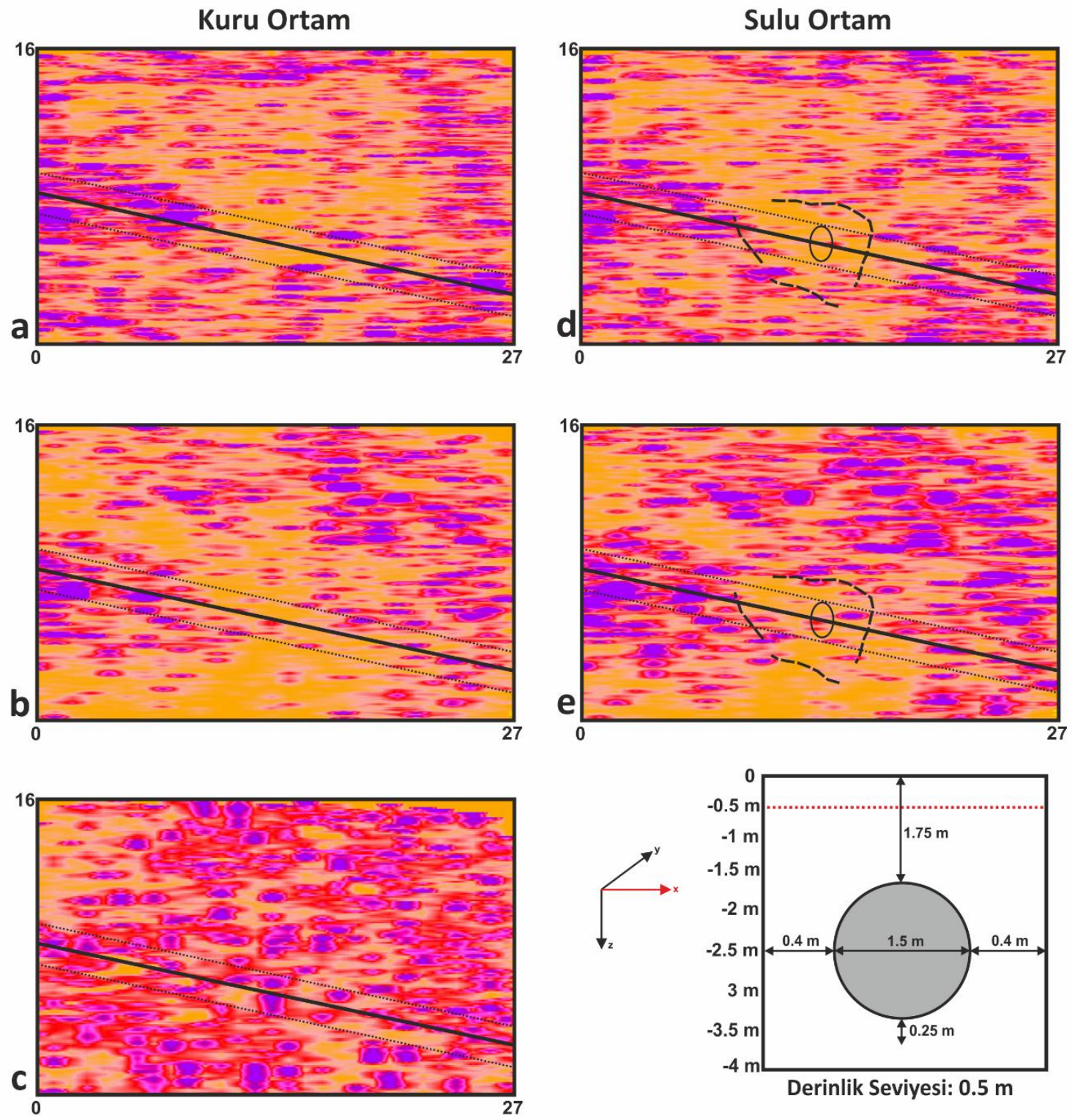

Şekil 8. $\mathrm{x}$-yönünde $0,5 \mathrm{~m}$ derinlik seviyesi için yeraltı görüntüsü. 

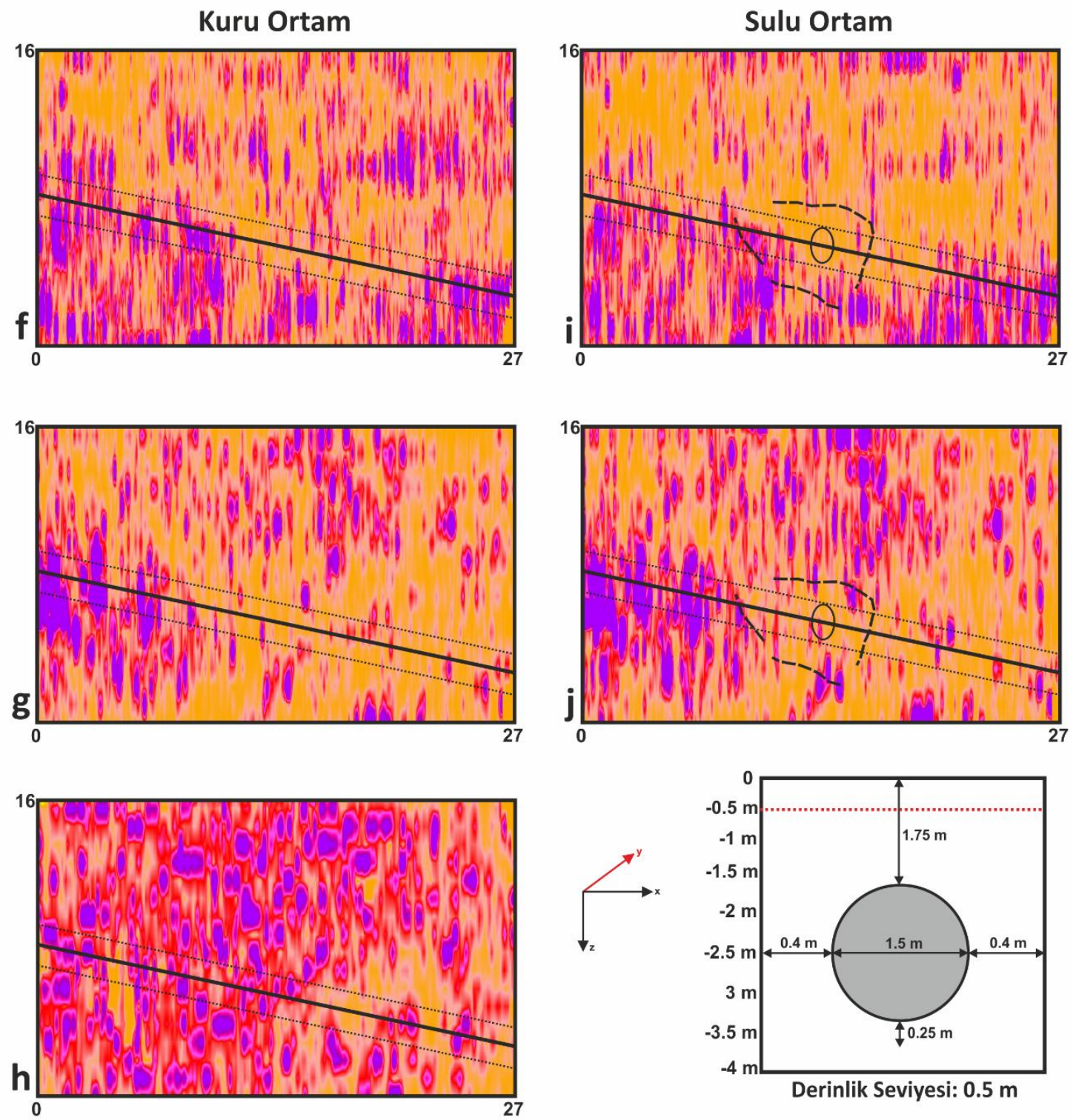

Şekil 9. y-yönünde $0,5 \mathrm{~m}$ derinlik seviyesi için yeraltı görüntüsü. 

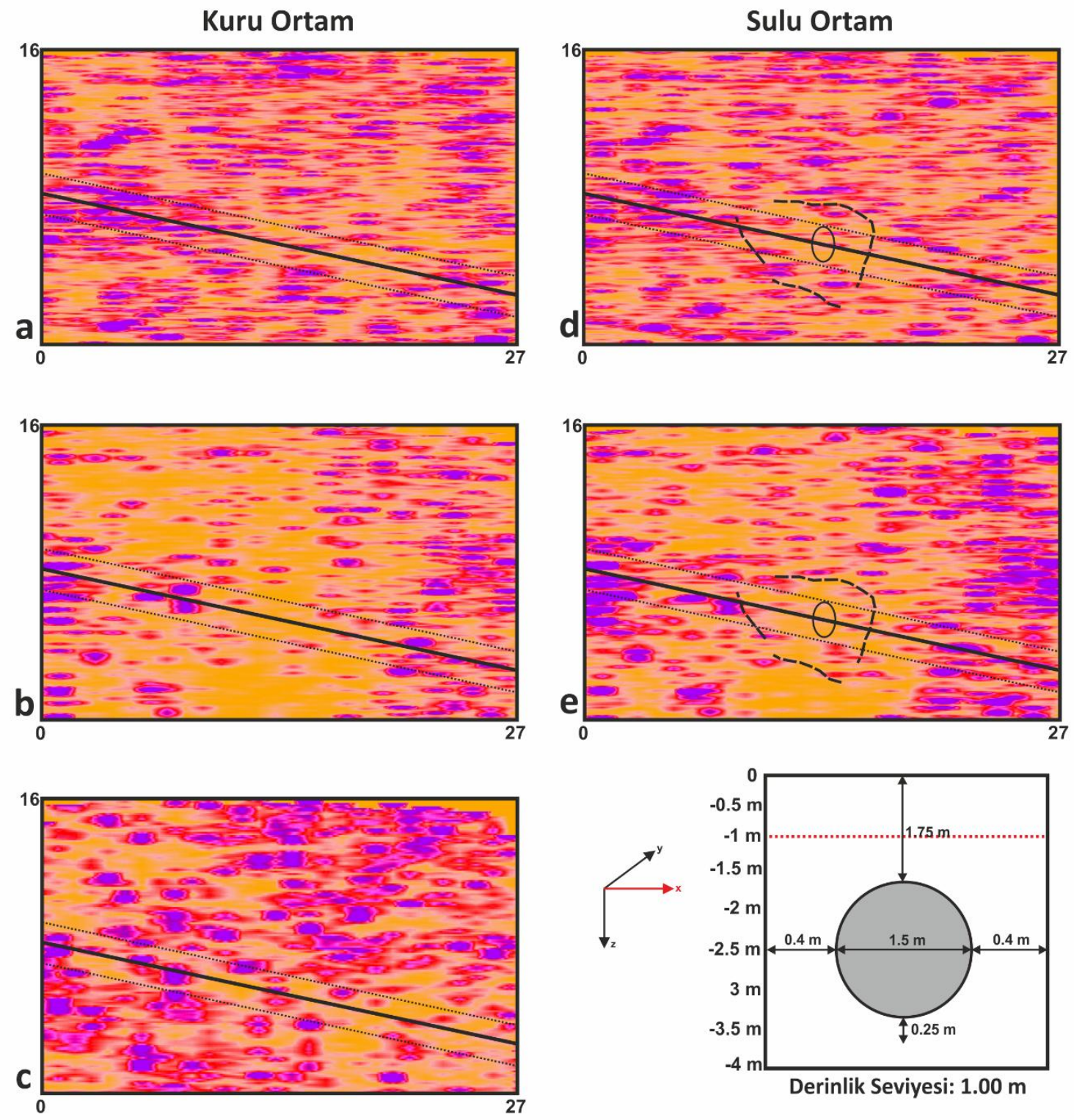

Şekil 10. $x$-yönünde $1 \mathrm{~m}$ derinlik seviyesi için yeraltı görüntüsü. 

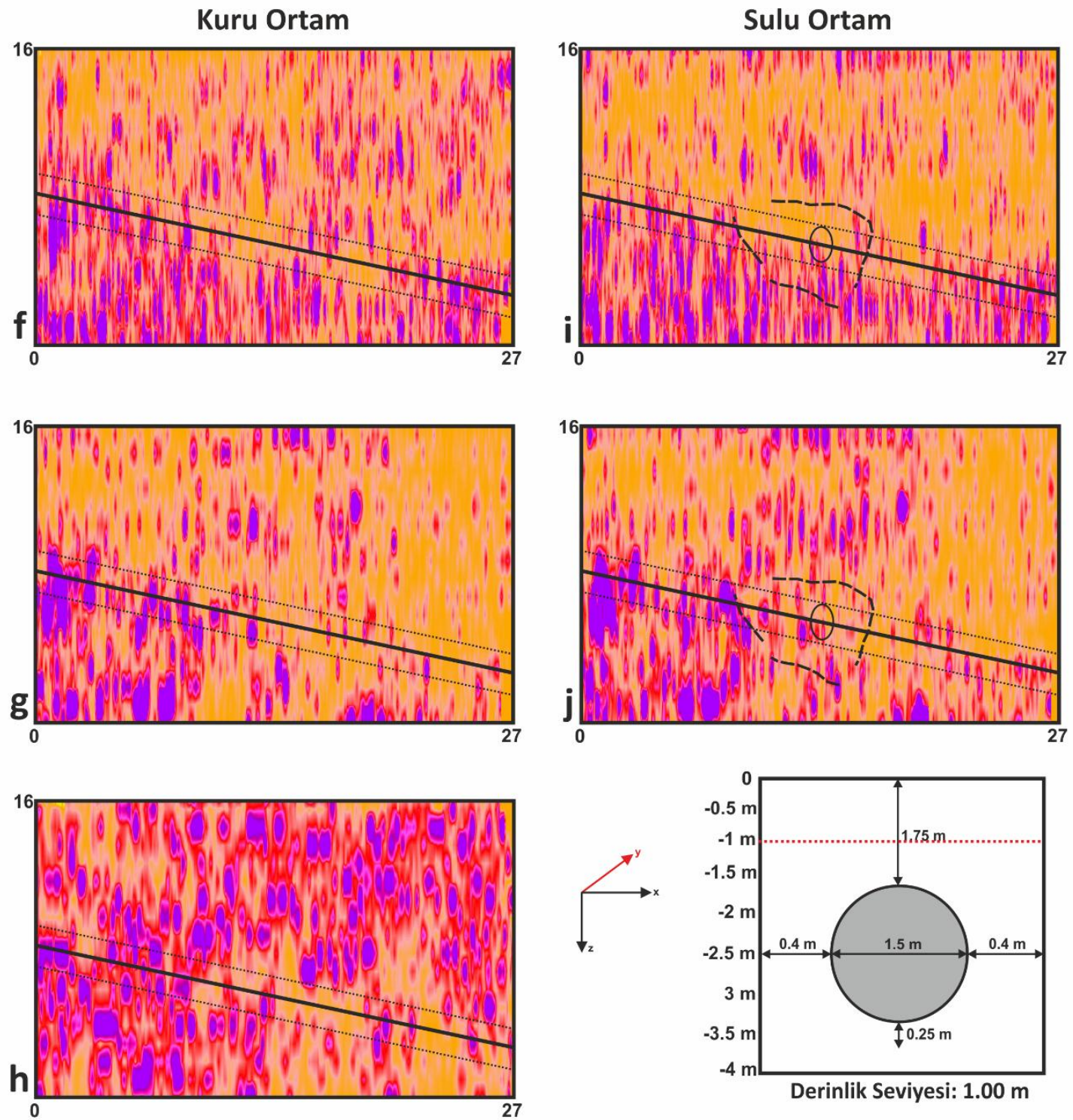

Şekil 11. y-yönünde $1 \mathrm{~m}$ derinlik seviyesi için yeraltı görüntüsü.

$160 \mathrm{MHz}$ ve $625 \mathrm{MHz}$ lik iki farklı frekansta alınan ölçüm verisinde konumu ve büyüklüğü bilinen CTP borunun varlığı tespit edilememiştir (Şekil 8-11; a ve b kesitleri). Ancak CTP boru hattına yüzeyden indirilen boruyla hattın etrafına bırakılan sudan dolayı nemli ortamın varlığı tespit edilmiştir (Şekil 8-11; d ve e kesitleri). CTP borunun tespit edilemediğinden emin olmak için 1 hafta sonra $250 \mathrm{MHz}$ anten ile tekrar ölçüm alınmıștır, elde edilen kesitlerde CTP boru yine tespit edilememiştir (Şekil 8-11; c kesiti).

\section{SONUÇ VE ÖNERI}

Elde edilen sonuçlarda konumu ve büyüklüğü bilinen CTP boru tespit edilememiş buna karşın etrafındaki su tespit edilmiştir. Borunun tespit edilememesinin nedeni boruyu çevreleyen toprağın ve yastıklama malzemenin elektromanyetik özelliklerinin boru malzemesindekilerle aynı büyüklükte olmasından kaynaklanabileceği düşünülmektedir. CTP doğada var olmayan cam elyafı ile doymamış polyester reçinenin birleşmesinden oluşan kompozit bir malzemedir. Malzemenin bir özelliği de mükemmel yalıtkan olması ve manyetik alan oluşturmamasıdır. Bu malzemeden üretilen borunun yeraltında tespit edilememesinin bir diğer nedeni olabilir. Sulama sahasında doğalgaz boru hattı, karayolu, demiryolu, yüksek hızlı tren gibi üst yapı ve alt yapı ile çakışan bölgelerde borunun tespiti amacıyla alüminyum malzeme ile sarılması önerilmektedir. 


\section{Teşekkür ve Katkı Belirtme}

Ölçümlerin gerçekleşmesi için izin veren DSİ 19. Bölge Müdürlüğü ve tüm personeline teşekkürlerimizi sunarız. Bu çalışma Sivas Cumhuriyet Üniversitesi, Fen Bilimleri Enstitüsü, Jeofizik ABD'da Yüksek Lisans'ını tamamlayan Hakan KÜTÜKCÜOĞLUGIL'in tezinin konusu olup bir kısmını içermektedir.

\section{Yazar Katkıları}

Yazarlar çalışmaya eşit oranlı katkı sunmuşlardır.

\section{Çıkar Çatışması}

Makale yazarları aralarında herhangi bir çıkar çatışması olmadığııı beyan ederler.

\section{KAYNAKÇA}

[1] H. Kütükcüoğlugil, "Yer radarı (GPR) yöntemi ile su boru hatlarında sızıntı konumlarının tespiti", Sivas Cumhuriyet Üniversitesi, Fen Bilimleri Enstitüsü, Jeofizik Mühendisliği ABD, Yüksek Lisans Tezi. 2020.

[2] G.U. Aldaş, S. Kadığlu, E.U. Ulugergerli, "The effects of concealed discontinuities in blast design pattern", 4th Int'l Scientific and Technical Conference of Young Scientists and Specialists. St. Petersburg-RUSSIA. pp.6-7, 2004.

[3] D. Erik, S. Koşaroğlu, "Evaporitik sahalardaki karstik boşlukların, yer radarı (GPR) yönetimi ile tespiti”, Ulusal Mühendislik Jeolojisi - Jeoteknik Sempozyumu. p.7, 2017.

[4] A.K. Benson, A. K, "Applications of ground penetrating radar in assessing some geological hazards: Examples of groundwater contaminants, faults, cavities", Journal of Applied Geophysics, vol. 33 (1-3), pp.177-193, 1995.
[5] G.S. Cezar, P.L.F. Rocha, A. Baurque, A. Costa, A, "Two Brazilian archeological sites investigated br GPR: Serrano and Morro Grande", Journal of Applied Geophysics, vol. 47 (3-4), pp.227-240, 2001.

[6] D. Ayala-Caberra, J. Izquierdo, S.J. Ocana-Levario, R. Perez-Garcia, "3d model construction of water supply system pipes based on gpr images", 7th International Congress on Environmental Modelling and Software - San Diego, California, USA , pp. 1-8, June 2014.

[7] T.S. Amran, P.M. İsmail, M.R. Ahmed, M.S.M. Amin, S. Sani, N.A. Masenwat, A.M. İsmail, S. Abdülhamid, "Detection of underground water distribution piping system and leakages using ground penetrating radar (GPR)", AIP Conference Proceedings, p. 1799, 2017.

[8] J. Kavi, "Detection of buried non-metallic (plastic and frp composite) pipes using GPR and IRT", Benjamin M. Statler College of Engineering and Mineral Resources at West Virginia University (Graduate Theses)", p.211, 2018. 